\title{
Ring-Closing Synthesis of Dibenzothiophene Sulfonium Salts and Their Use as Leaving Groups for Aromatic ${ }^{18} \mathrm{~F}$-Fluorination
}

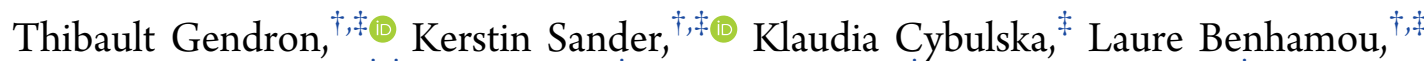
Pak Kwan Brian Sin, ${ }^{\dagger, \ddagger}$ Aqsa Khan, ${ }^{\ddagger}$ Michael Wood, ${ }^{\ddagger}$ Michael J. Porter, ${ }^{\ddagger}$ and Erik Årstad ${ }^{\ddagger},,+0$

${ }^{\dagger}$ Institute of Nuclear Medicine, University College London, 235 Euston Road (T-5), London NW1 2BU, United Kingdom

${ }^{\ddagger}$ Department of Chemistry, University College London, 20 Gordon Street, London WC1H 0AJ, United Kingdom

\section{Supporting Information}

ABSTRACT: Herein, we report a novel intramolecular ring-closing reaction of biaryl thioethers that give access to highly functionalized dibenzothiophene sulfonium salts under mild conditions. The resulting precursors react regioselectively with $\left[{ }^{18} \mathrm{~F}\right]$ fluoride to give $\left[{ }^{18} \mathrm{~F}\right]$ fluoroarenes in predictable radiochemical yields. The strategy expands the available radiochemical space and provides superior labeling efficiency for clinically relevant PET tracers.

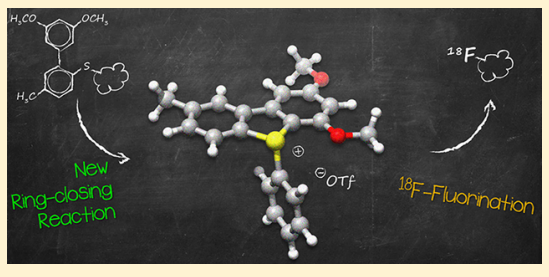

\section{INTRODUCTION}

Fluorine-18 is uniquely suited for imaging with positron emission tomography (PET) due to its favorable half-life (110 $\mathrm{min})$ and high-efficiency, low-energy positron emission $\left(97 \% \beta+, E_{\text {mean }}=0.250 \mathrm{keV}\right)$. The versatile properties of $\mathrm{C}-\mathrm{F}$ bonds and their widespread use in medicinal chemistry further contribute to the appeal of fluorine-18 for diagnostic imaging and pharmaceutical research. Yet, incorporation of $\left[{ }^{18} \mathrm{~F}\right]$ fluoride into biologically active molecules is often difficult, if not impossible, to achieve. Nucleophilic $S_{N} 2$ and $S_{N} A r$ substitution reactions with $\left[{ }^{18} \mathrm{~F}\right]$ fluoride remain the most widely used strategies for labeling, as they are technically simple and robust. However, target compounds are rarely suitable for this approach, and radiotracers are therefore typically modified with fluorinated aliphatic side chains, or highly activated aromatic groups, to allow labeling to take place. Since the development of $S_{N} 2$ reactions with $\left[{ }^{18} \mathrm{~F}\right]$ fluoride more than 30 years ago, continuous efforts have been made to expand the radiochemical space. ${ }^{1-3}$ Recent chemical insights have re-invigorated the field and led to the discovery of several innovative strategies for radiofluorination. New types of precursors, including aryl boronic acids and esters, ${ }^{4-6}$ preformed $\mathrm{Pd}^{\mathrm{IV}}$ or $\mathrm{Ni}^{\mathrm{II}}$ complexes, ${ }^{7,8} \mathrm{~N}$-aryl sydnones, ${ }^{9}$ uronium salts, ${ }^{10}$ iodonium ylides, ${ }^{11,12}$ and arylsulfonium salts, ${ }^{13-15}$ now allow direct fluorination of aromatic ring systems that until recently were beyond reach. While these methods certainly have expanded the radiochemical space, their impact on clinical PET remains limited. ${ }^{16}$ This reflects the difficulties in preparing highly complex precursors for labeling, shortcomings of the radiochemical reactions, and, for metalbased methods, concerns about toxicity.

We have previously reported that triarylsulfonium salts allow direct ${ }^{18}$ F-fluorination of small molecule drug-like compounds containing non-activated and electron-deficient aromatic rings. ${ }^{14}$ The appeal of this approach is the ability to label a broad range of bioactive molecules under conditions that mirror conventional substitution reactions with $\left[{ }^{18} \mathrm{~F}\right]$ fluoride. How- ever, few reactions are available to form aryl-sulfonium salts, and access to the precursors for labeling depends on protection strategies to enable selective $S$-arylation of thioethers in the presence of other reactive functional groups. Here we report that dibenzothiophene sulfonium salts can be accessed through intramolecular cyclization of biaryl thioethers under mild conditions. The strategy overcomes the synthetic limitations of triarylsulfonium salts and provides a flexible platform for the design of leaving groups for aromatic ${ }^{18} \mathrm{~F}$-fluorination (Figure $1)$.

Dibenzothiophene sulfonium salts have previously been obtained through activation of aromatic sulfoxides with
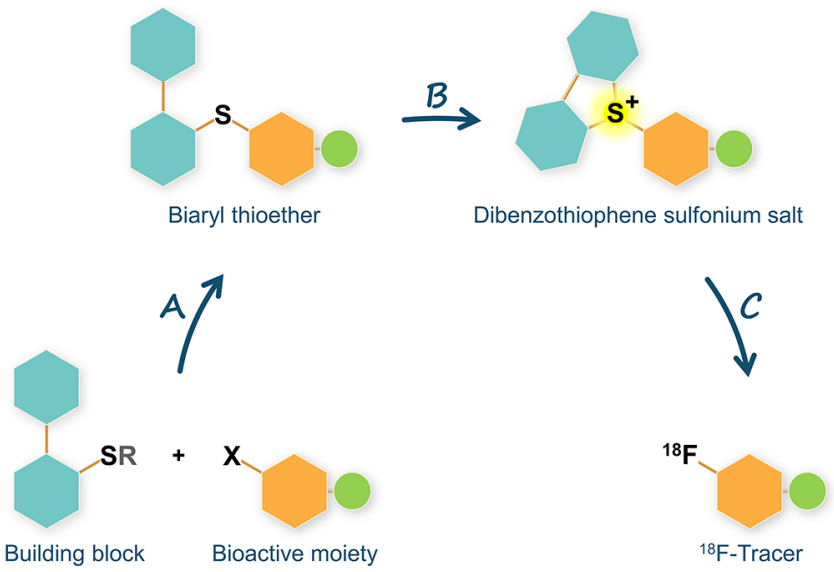

Figure 1. Dibenzothiophene sulfonium salts as leaving groups for aromatic ${ }^{18} \mathrm{~F}$-fluorination. A: coupling of a biaryl building block with the structure of interest; $\mathrm{B}$ : ring-closing to form the dibenzothiophene sulfonium salt precursor; $\mathrm{C}:{ }^{18} \mathrm{~F}$-fluorination. $\mathrm{X}=\mathrm{Br}$, I.

Received: July 3, 2018

Published: August 22, 2018 
trifluoromethanesulfonic acid, or trifluoromethanesulfonic anhydride, to form highly reactive Pummerer-type intermediates that trigger intramolmolecular cyclization. ${ }^{17-19}$ We envisaged that direct $S$-activation of thioethers with a source of electrophilic halogen, e.g. N-chlorosuccinimide (NCS), ${ }^{20,21}$ could provide a more concise and flexible synthetic route to the target compounds.

\section{RESULTS AND DISCUSSION}

During initial studies with the unsubstituted biaryl thioether 1a, we found that treatment with NCS and silver triflate afforded the target dibenzothiophene sulfonium salt $\mathbf{2 a}$, albeit in poor yield (Table 1). To investigate the influence of electron-donating groups on the ring-closing reaction, a small library of biaryl thioethers was prepared. Introduction of methyl groups to rings $\mathrm{A}$ and $\mathrm{B}$, as for $\mathbf{1 b}$, had a marginal impact on the cyclization yield. However, addition of a tert-butyl substituent on ring A to give $1 \mathrm{c}$ substantially increased the reactivity ( $14 \%$ and $56 \%$ for $\mathbf{2 b}$ and 2c, respectively). Finally, decoration of ring system A with methoxy groups, as for $\mathbf{1 d}$ and $\mathbf{1 e}$, allowed highly efficient ringclosure, with formation of $2 \mathrm{~d}$ and $2 \mathrm{e}$ in $82 \%$ and $79 \%$ yield, respectively. The sulfonium triflate salts were obtained as stable, non-hygroscopic solids and could readily be purified by liquid/ liquid extraction and column chromatography on silica gel.

Table 1. Synthesis and Labeling of Dibenzothiophene Sulfonium Salts $2 \mathrm{a}-\mathrm{e}^{a}$
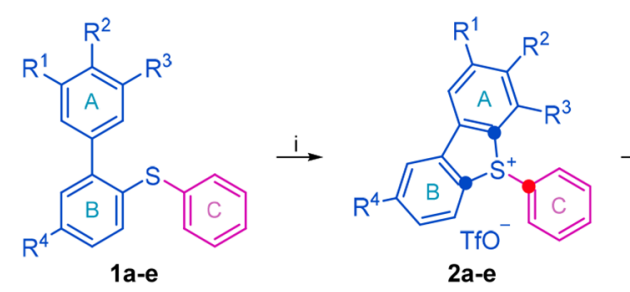

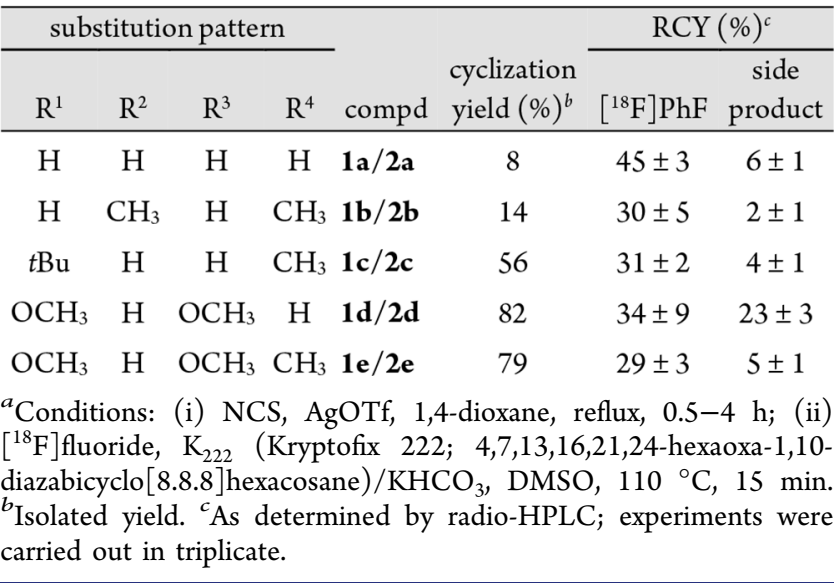

Dibenzothiophene sulfonium salts can potentially react with $\left[{ }^{18} \mathrm{~F}\right]$ fluoride by ipso-attack at any of the three $S$-substituted carbons, resulting in either release of the desired ${ }^{18} \mathrm{~F}$-fluorinated arene, or side product formation by opening of the heterocyclic ring system (red vs blue positions, respectively, Scheme on Table 1). To assess the reactivity profile of this novel class of leaving groups, the labeling efficiency of compounds $2 a-e$ with $\left[{ }^{18} \mathrm{~F}\right]$ fluoride was investigated (Table 1 ). The radiochemical reactions were carried out with $5 \mathrm{mg}$ precursor in dimethylsulfoxide (DMSO) at $110{ }^{\circ} \mathrm{C}$ for $15 \mathrm{~min}$. The unsubstituted analog $2 \mathrm{a}$ afforded $\left[{ }^{18} \mathrm{~F}\right]$ fluorobenzene in $45 \pm 3 \%$ radio-
Scheme 1. Synthesis of Building Block 5a,b and Coupling of the Biaryl Thiol Moiety with Aryl Halides ${ }^{a}$
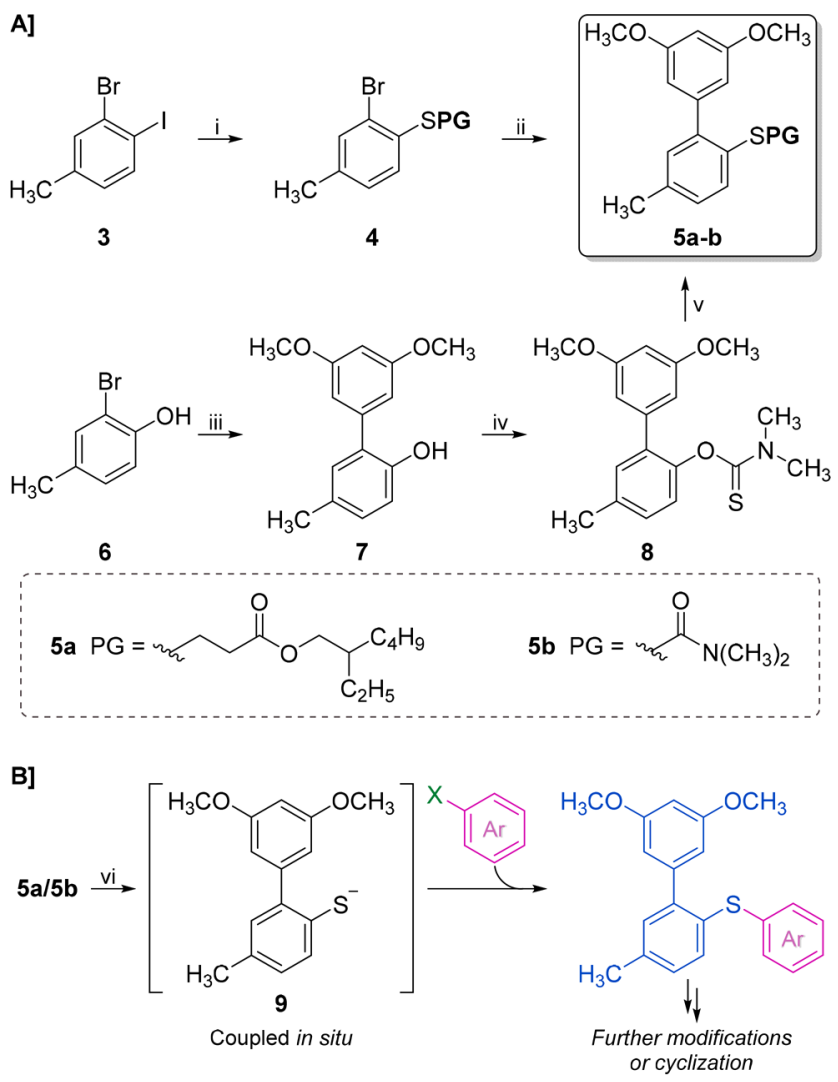

${ }^{a}$ Conditions: (i) 2-ethylhexyl-3-mercaptopropionate, $\mathrm{Pd}_{2}(\mathrm{dba})_{3}$, Xantphos, $\mathrm{Et}_{3} \mathrm{~N}$, toluene, reflux, $2 \mathrm{~h}, 96 \%$; (ii) 3,5-dimethoxyphenylboronic acid, PEPPSI-IPr, $\mathrm{K}_{2} \mathrm{CO}_{3}$, toluene/water, reflux, $2 \mathrm{~h}, 95 \%$; (iii) 3,5-dimethoxyphenylboronic acid, $\mathrm{Pd}(\mathrm{OAc})_{2}, i \mathrm{PrNH}_{2}$, water, reflux, 24 h, 93\%; (iv) a) $\mathrm{NaH}, \mathrm{THF}, 0{ }^{\circ} \mathrm{C}-\mathrm{RT}, 30 \mathrm{~min}, \mathrm{~b}$ ) dimethylthiocarbamoyl chloride, $70{ }^{\circ} \mathrm{C}, 16 \mathrm{~h}, 89 \%$; (v) neat, $290{ }^{\circ} \mathrm{C}$, $3 \mathrm{~h}, 97 \%$; (vi) tBuOK, $\mathrm{Pd}_{2}(\mathrm{dba})_{3}$, DPEPhos (bis[(2-diphenylphosphino)phenyl] ether), toluene, reflux. $\mathrm{X}=\mathrm{Br}$, I.

chemical yield (RCY) as determined by radio-high-performance liquid chromatography (radio-HPLC), whereas the more electron-rich precursors $\mathbf{2 b}-\mathbf{e}$ gave RCYs in the range of $29-34 \%$. High regioselectivity in favor of $\left[{ }^{18} \mathrm{~F}\right]$ fluorobenzene formation was observed for all cases, with the exception of precursor $2 \mathrm{~d}$. In the latter case, introduction of an electron donating methyl substituent on ring $B$, to give precursor $2 \mathbf{e}$, restored regioselectivity. Of the compounds investigated, sulfonium salt 2e offered the optimal balance between cyclization yield, reactivity with $\left[{ }^{18} \mathrm{~F}\right]$ fluoride and regioselectivity of the labeling reaction.

To allow direct incorporation of the optimized biaryl thiol moiety 1e into complex structures (Figure 1, Step A), we designed the two building blocks $\mathbf{5} \mathbf{a}-\mathbf{b}$ and optimized their synthesis on multigram scale (Scheme 1A). Briefly, 5a was obtained in two steps, starting with the Pd-catalyzed coupling of 2-bromo-1-iodo-4-methylbenzene 3 with 2-ethylhexyl-3mercaptopropionate to form protected thiol $4 .^{22}$ Subsequent Suzuki coupling of 4 with 3,5-dimethoxyphenylboronic acid provided $\mathbf{5} \mathbf{a}$ in $91 \%$ overall yield. Compound $\mathbf{5} \mathbf{b}$ was obtained in three steps; Suzuki coupling of 2-bromo-4-methylphenol 6 with 3,5-dimethoxyphenylboronic acid provided 7, which was then reacted with dimethylthiocarbamoyl chloride to give 8 . The final 
step in the sequence was a Newman-Kwart rearrangement under thermal conditions, ${ }^{23,24}$ which provided $\mathbf{5 b}$ in $80 \%$ overall yield. Although the building blocks $5 \mathbf{a}-\mathbf{b}$ underwent rapid deprotection under basic conditions (Scheme 1B), we were not able to isolate the corresponding thiol in synthetically useful yields, as 9 rapidly oxidized to form the corresponding disulfide. To circumvent this problem, we developed a one-pot procedure for deprotection of $\mathbf{5 a - b}$ and subsequent Pd-mediated coupling of 9 with aryl halides in situ (Scheme 1B) by combining previously reported methods for the individual steps. ${ }^{22,25}$ This provided a flexible, concise, and high-yielding route to install the biaryl thioether moiety. Conveniently, the strategy also avoids the need to handle any foul smelling compounds which otherwise can be problematic with organosulfur chemistry.

While the synthesis of $\mathbf{5 a}$ is shorter and higher yielding than the route to $\mathbf{5 b}$, deprotection of $\mathbf{5 a}$ results in the formation of 2-ethylhexyl acrylate as a byproduct, which can give rise to side products and complicate purification. The building block $\mathbf{5 b}$ offers several advantages over $\mathbf{5 a}$ in that it is a crystalline solid and the carbamothioate protecting group simplifies purification and handling. However, the high temperature required for the Newman-Kwart rearrangement makes this transformation nontrivial, and deprotection of $\mathbf{5 b}$ requires excess potassium tertbutoxide, which may compromise base-sensitive functional groups.

With a method in hand to couple the biaryl thiol moiety with functionalized aryls, we optimized the conditions for the cyclization reaction to give the target dibenzothiophene sulfonium salts. To ultimately allow labeling of the PET tracer 3 - $\left[{ }^{18} \mathrm{~F}\right]$ fluoro-5-(pyridin-3-yle thynyl)benzonitrile $\left(\left[{ }^{18} \mathrm{~F}\right] \mathrm{FPEB}\right),{ }^{26,27}$ the thioether 10a was prepared ( 2 steps from 5a, $65 \%$ overall yield). Attempted cyclization by treatment of 10a with NCS and silver triflate gave a disappointing $6 \%$ yield of the corresponding sulfonium salt 11 a, as determined by HPLC (Table 2, entry 1). A comparable yield was obtained with NCS

Table 2. Optimization of the Ring-Closing Reaction

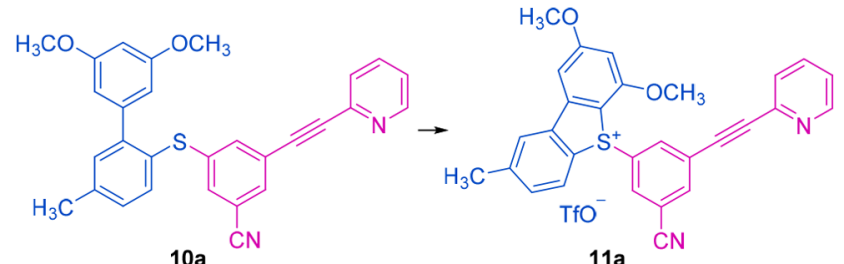

\begin{tabular}{|c|c|c|c|c|c|c|}
\hline entry & $\begin{array}{c}\mathrm{Cl}^{+} \\
\text {source }\end{array}$ & additive & solvent & $\begin{array}{l}\text { temp } \\
\left({ }^{\circ} \mathrm{C}\right)\end{array}$ & time & $\begin{array}{c}\text { HPLC } \\
\text { yield (\%) }\end{array}$ \\
\hline 1 & NCS & AgOTf & 1,4-dioxane & 100 & $2.5 \mathrm{~h}$ & 6 \\
\hline 2 & NCS & $\mathrm{La}(\mathrm{OTf})_{3}$ & 1,4-dioxane & 100 & $2.5 \mathrm{~h}$ & 7 \\
\hline 3 & NCS & $\mathrm{Bi}(\mathrm{OTf})_{3}$ & 1,4-dioxane & 100 & $2.5 \mathrm{~h}$ & 48 \\
\hline 4 & NCS & $\mathrm{Bi}(\mathrm{OTf})_{3}$ & $\mathrm{MeCN}$ & 80 & $2.5 \mathrm{~h}$ & 79 \\
\hline 5 & NCS & $\mathrm{Bi}(\mathrm{OTf})_{3}$ & $\mathrm{MeCN}$ & 20 & $15 \min$ & 65 \\
\hline 6 & - & $\mathrm{Bi}(\mathrm{OTf})_{3}$ & $\mathrm{MeCN}$ & 20 & $15 \mathrm{~min}$ & 0 \\
\hline 7 & NCS & - & $\mathrm{MeCN}$ & 20 & $15 \mathrm{~min}$ & 0 \\
\hline 8 & NCS & TfOH & $\mathrm{MeCN}$ & 20 & $15 \min$ & 58 \\
\hline 9 & $\mathrm{Ca}(\mathrm{OCl})_{2}$ & $\begin{array}{l}\text { acetate } \\
\text { buffer }^{a}\end{array}$ & $\begin{array}{c}\text { acetone/ } \\
\text { water }\end{array}$ & 20 & $15 \mathrm{~min}$ & 43 \\
\hline
\end{tabular}

${ }^{a}$ Aqueous acetate buffer, $1 \mathrm{M}, \mathrm{pH} 4$. in the presence of lanthanum(III) triflate, whereas bismuth(III) triflate greatly increased the reactivity and provided 11a in $48 \%$ yield (Table 2, entries 2 and 3 ). Changing the solvent from 1,4-dioxane to acetonitrile $(\mathrm{MeCN})$ further increased the yield to $79 \%$. Remarkably, under these conditions, thioether $10 \mathrm{a}$ cyclized almost instantly at ambient temperature to give the target sulfonium salt 11a in $65 \%$ analytical yield (Table 2, entry 5) (Method A). When these conditions were applied on a preparative scale, 11a was obtained in $82 \%$ yield. As bismuth(III) triflate can liberate trifluoromethanesulfonic acid, $^{28}$ we hypothesized that the ring-closing reaction was promoted by formation of a superelectrophile through Brønsted acid activation of NCS (Scheme 2). ${ }^{29,30}$ Consistent with this, trifluoromethanesulfonic acid in combination with NCS also mediated rapid cyclization of $\mathbf{1 0 a}$ at room temperature (Table 2, entry 8$)$.

Scheme 2. Proposed Mechanism for the Ring-Closing Reaction<smiles>C[I+]I</smiles><smiles>C#C[C-][C-]=C1CCC(=O)N1Cl</smiles><smiles>[R][SH](CC[CH+])c1ccc(C)cc1-c1cc(OC)cc(OC)c1</smiles>$$
\text { O }
$$

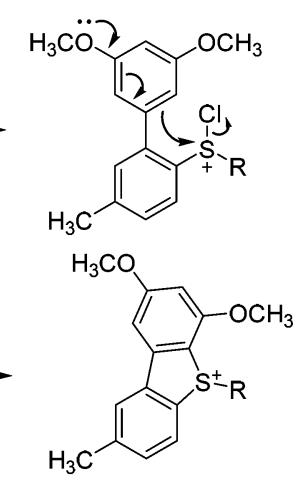

On the basis of these findings, we propose the following mechanism for the ring-closing reaction: protonation of NCS triggers attack of chlorine on the thioether group to give an intermediate chlorosulfonium salt, which subsequently rearranges through an intramolecular $S_{\mathrm{E}} \mathrm{Ar}$ reaction to yield the target dibenzothiophene sulfonium salt (Scheme 2).

To allow cyclization under neutral conditions, we explored alternative sources of electrophilic chlorine. Several hypochlorite salts mediated ring-closing of the thioether 10a; however, yields varied considerably, and chlorination of the dimethoxy-substituted aromatic group became a prominent side reaction (results not shown). Eventually, we found that calcium hypochlorite, in an acetate-buffered $(\mathrm{pH} 4)$ water-acetone solvent system, ${ }^{31}$ reacted cleanly with 10 a to give the target sulfonium salt 11a in $43 \%$ yield within $15 \mathrm{~min}$ at room temperature (Table 2, entry 9) (Method B). The latter system is appealing, as it is exceptionally mild and relies exclusively on low-toxicity, biocompatible components.

To investigate the scope of the ring-closing reaction, we prepared a library of biaryl thioethers (Table 3). The compounds $10 \mathrm{~b}-\mathrm{k}$ were obtained by $\mathrm{Pd}$-mediated coupling of the building block 5a with the respective aryl bromides or iodides (see Supporting Information (SI)). When treated with NCS and bismuth(III) triflate (Method A), the thioethers $\mathbf{1 0 b}-\mathbf{i}$ rapidly cyclized ( $5 \mathrm{~min}$ to $2 \mathrm{~h}$ ) under ambient conditions 
Table 3. Scope Study for Aromatic ${ }^{18}$ F-Fluorination Using Dibenzothiophene Sulfonium Salts as Precursors ${ }^{a}$

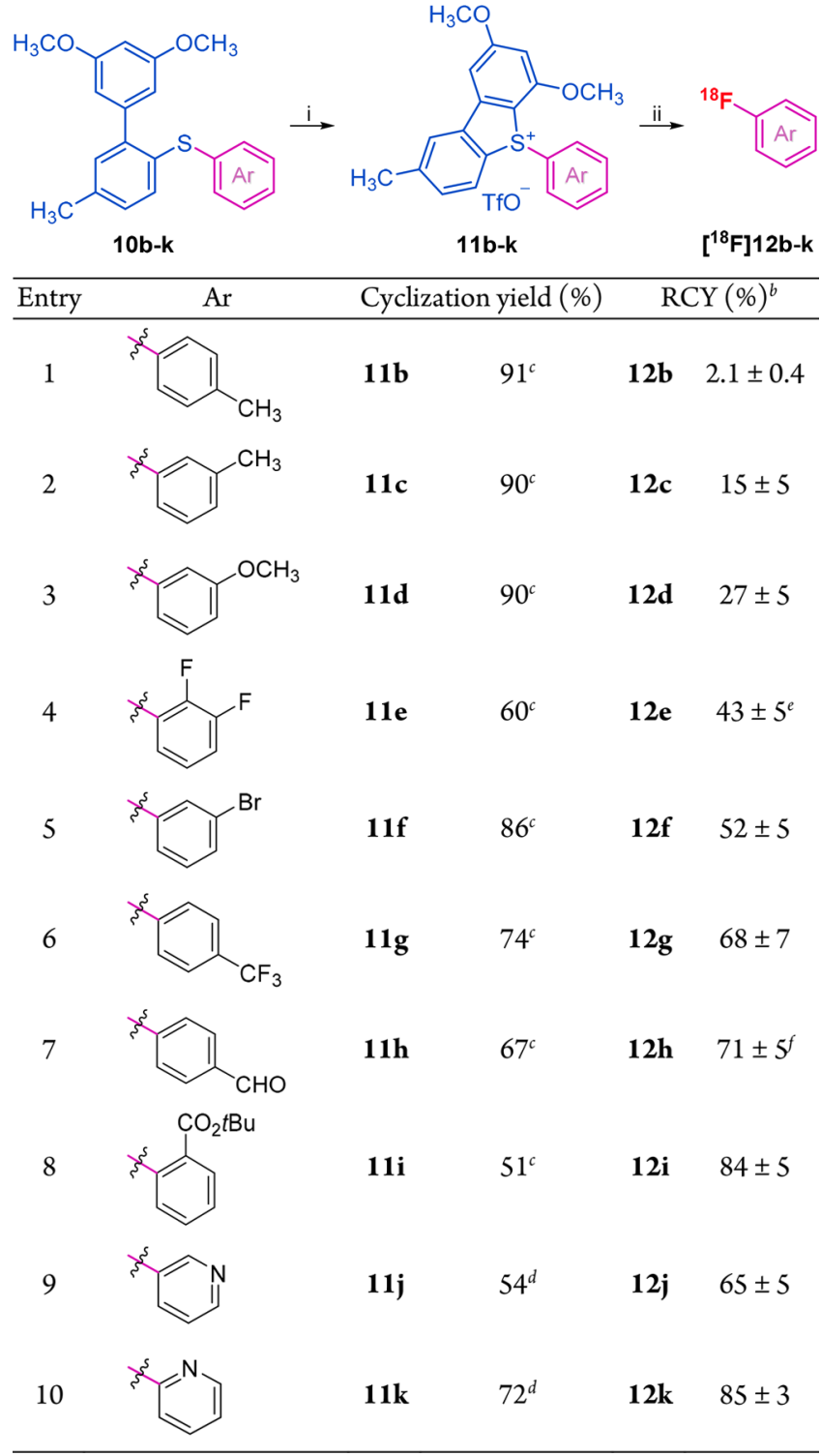

${ }^{a}$ Conditions: (i) Method A: NCS, Bi(OTf) $)_{3}, \mathrm{MeCN}, \mathrm{RT}, 5 \mathrm{~min}-2 \mathrm{~h}$ or Method $\mathrm{B}$ : $\mathrm{Ca}(\mathrm{OCl})_{2}$, acetate buffer $\mathrm{pH} 4$, acetone, $0{ }^{\circ} \mathrm{C}-\mathrm{RT}$, $15 \mathrm{~min}$; (ii) $\left[{ }^{18} \mathrm{~F}\right]$ fluoride, $\mathrm{K}_{222} / \mathrm{KHCO}_{3}$, DMSO, $110^{\circ} \mathrm{C}$, 15 min. ${ }^{b} \mathrm{As}$ determined by radio-HPLC. Experiments were carried out in triplicate. ${ }^{c}$ Method A was used. ${ }^{d}$ Method B was used. ${ }^{e}$ Labeling at $80{ }^{\circ} \mathrm{C} .{ }^{f}$ Labeling at $75{ }^{\circ} \mathrm{C}$.

(room temperature, open to air) to give the target sulfonium salts $\mathbf{1 1 b}-\mathbf{i}$ in good to excellent yields. Although electron-rich systems proved the most reactive, ring-closing of electrondeficient substrates, i.e. $\mathbf{1 0 g}$ and $\mathbf{1 0 h}$, also proceeded cleanly and in good yields. Introduction of ortho substituents, as for $10 \mathrm{e}$ and 10i, had only a marginal impact on the reaction, and the sterically hindered tert-butyl ester $\mathbf{1 0 i}$ still afforded the corresponding sulfonium salt $\mathbf{1 1 i}$ in $51 \%$ yield (Table 3 , entries 4 and 8 ). However, the pyridyl-substituted thioethers $10 \mathbf{j}, \mathbf{k}$ failed to cyclize in the presence of NCS/bismuth(III) triflate, likely due to the electron-withdrawing effect caused by pyridinium salt formation with trifluoromethanesulfonic acid. In these cases, acetate-buffered calcium hypochlorite
(Method B) provided an efficient alternative and afforded the target sulfonium salts $\mathbf{1 1} \mathbf{j}, \mathbf{k}$ in $54 \%$ and $72 \%$ yields, respectively.

The dibenzothiophene sulfonium salts $\mathbf{1 1 b}-\mathbf{k}$ were subsequently used to investigate the scope of aromatic ${ }^{18} \mathrm{~F}$ fluorination (Table 3). To allow direct comparison, the radiochemical reactions were carried out using the nonoptimized conditions described above. The least reactive of the compounds, the tolyl salt $\mathbf{1 1 b}$, afforded $4-\left[{ }^{18} \mathrm{~F}\right]$ fluorotoluene in a modest $2 \%$ RCY (Table 3, entry 1 ). However, the regioisomer $11 \mathrm{c}$ reacted to give $3-\left[{ }^{18} \mathrm{~F}\right]$ fluorotoluene in a synthetically useful RCY of $15 \pm 5 \%$ (Table 3, entry 2). Formation of $3-\left[{ }^{18} \mathrm{~F}\right]$ fluoroanisole in $27 \pm 5 \%$ RCY demonstrates that dibenzothiophene sulfonium salts can allow labeling of electron-rich aryls, provided that the substitution pattern is favorable (Table 3, entry 3). Electron-deficient aryls and pyridines were labeled in high RCY (Table 3, entries 4-10). Notably, 3- $\left[{ }^{18} \mathrm{~F}\right]$ fluoropyridine, which is difficult to label with many other strategies, was formed in $65 \pm 5 \%$ RCY. The sterically hindered tert-butyl ester $11 \mathrm{i}$ proved highly reactive and gave $\left[{ }^{18} \mathrm{~F}\right] 12 \mathrm{i}$ in $84 \pm 5 \% \mathrm{RCY}$. However, labeling of $11 \mathrm{e}$ and $11 \mathrm{~h}$ was problematic under these conditions due to decomposition and side product formation. When the temperature was reduced from 110 to $80{ }^{\circ} \mathrm{C}$, $11 \mathrm{e}$ readily reacted to give $\left[{ }^{18} \mathrm{~F}\right]-1,2,3$-trifluorobenzene, a fragment of the PET tracer $\left[{ }^{11} \mathrm{C}\right]$ UCB-J,${ }^{32}$ in $43 \pm 5 \% \mathrm{RCY}$. In the case of $11 \mathrm{~h}$, the reaction proceeded cleanly at $75{ }^{\circ} \mathrm{C}$ to give $4-\left[{ }^{18} \mathrm{~F}\right]$ fluorobenzaldehyde, a well-established prosthetic labeling group, ${ }^{2}$ in $71 \% \mathrm{RCY}$.

To gain a deeper understanding of the fluorination mechanism and the regioselectivity of the reaction, density functional theory (DFT) calculations were performed. The M06-2X hybrid functional was used ${ }^{33}$ with the $6-31+G(d, p)$ basis set. Initial gas-phase calculations showed that the cation of salt 2e could form a fluoride adduct 13a (Figure 2). In the lowest-energy conformation Ia of this adduct, the sulfur atom adopts a trigonal bipyramidal geometry, with a lone pair occupying an equatorial site, and the fluorine atom and the methoxy-substituted aromatic ring occupying axial positions. The nature of the S-F interaction was probed using the quantum theory of atoms in molecules (QTAIM) approach: ${ }^{34}$ in ionic bonds, the electron density $\rho$ at the bond critical point is typically less than 0.10 , while its Laplacian $\nabla^{2} \rho$ has a positive value. For the $\mathrm{S}-\mathrm{F}$ bond in Ia, the calculated values were $\rho=0.09$ and $\nabla^{2} \rho=+0.17$, indicating that this is essentially an ionic interaction. ${ }^{35}$ This conclusion was reinforced by integration of the electron density in AIM basins: this gave net charges of -0.77 on the fluorine atom and +0.66 on the sulfur. Re-minimization of structure Ia under the SMD solvation model $^{36}$ with DMSO as solvent led to a lengthening of the S-F bond ( $2.54 \AA$ vs $2.00 \AA$ ) and an increase in its ionic nature (calculated charges of -0.94 and +0.51 on $F$ and $S$, respectively) but no substantial change in the structure of the sulfonium cation. All subsequent calculations were carried out with both gas-phase and solution-phase optimization, with similar results; the structures and energies presented below are for the solutionphase calculations (details of gas-phase calculations are provided in the SI).

A second energy minimum was located for the sulfonium fluoride salt 13a: conformation IIa, in which the phenyl group and fluoride ion occupy the axial positions and both benzene rings of the dibenzothiophene moiety are equatorially disposed. Conformation IIa has a free energy $8.6 \mathrm{~kJ} \mathrm{~mol}^{-1}$ higher than that of conformation Ia. A transition state linking Ia and IIa, labeled TS-IIIa, could also be located, with a free energy $22.2 \mathrm{~kJ} \mathrm{~mol}^{-1}$ 


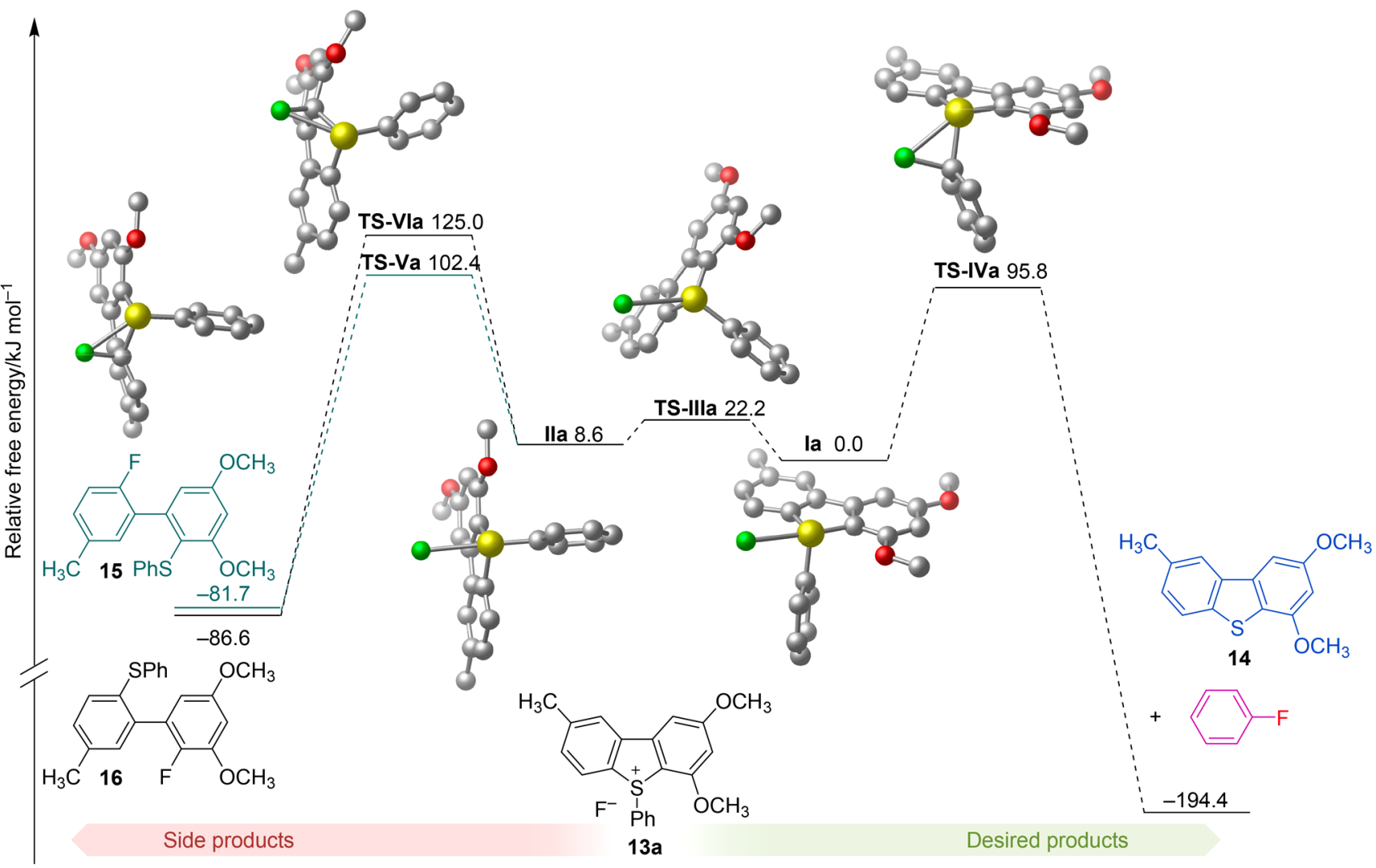

Figure 2. Calculated free energy profile for formation of fluorobenzene and biphenyls $\mathbf{1 5}$ and $\mathbf{1 6}$ from sulfonium fluoride salt 13a. Structures are optimized with M06-2X/6-31+G(d,p), SMD solvation in DMSO. Hydrogen atoms are omitted for clarity.

above that of Ia. ${ }^{37}$ This low barrier, compared to the barriers for product formation (vide infra), suggests that the CurtinHammett principle will be applicable and that the relative rates of product formation will be determined by the energies of the transition states leading to product, rather than by the relative populations of conformers Ia and IIa.

From intermediate Ia, two possible routes for the formation of fluorobenzene and dibenzothiophene 14 were considered: a stepwise $S_{N} A r$ mechanism proceeding through a Meisenheimer complex, and a concerted process which could be viewed either as a direct nucleophilic aromatic substitution or as a reductive elimination from sulfur. After extensive searching, no local minimum corresponding to a Meisenheimer complex could be located; instead a concerted mechanism, passing through a single transition state TS-IVa, was identified. Similar concerted mechanisms have been determined in computational studies of nucleophilic aromatic fluorinations of iodonium(III) ylides and diaryliodonium salts, ${ }^{12,38}$ aryl fluorosulfonates, ${ }^{39}$ and phenoluronium adducts. ${ }^{10}$

Analogous transition states TS-Va and TS-VIa could be located, connecting conformation IIa of the sulfonium fluoride salt 13a to biaryls 15 and 16, respectively. These transition states were found 6.6 and $29.2 \mathrm{~kJ} \mathrm{~mol}^{-1}$, respectively, higher in energy than TS-IVa, in accord with the good selectivity for attack on the phenyl group seen experimentally.

Several other dibenzothiophenium fluorides $\mathbf{1 3 b}-\mathbf{k}$, corresponding to the triflates $1 \mathbf{1} \mathbf{b}-\mathbf{k}$, were modeled to examine any correlation between calculated activation energies and experimental reactivity. Ground-state conformations and transition states for fluoride attack on each of the three aromatic rings were identified. Due to the difficulty in calculating a meaningful energy for the solvated fluoride ion, the fluoride salts $13 \mathrm{a}-\mathrm{k}$ were taken as the zero-energy baseline for each of these calculations (Table S5, SI). High correlation $\left(R^{2}=0.98\right)$ was observed between calculated activation energy for attack on the isolated aromatic ring and RCY (Figure S13, SI); i.e., compounds with low calculated activation energy gave high RCYs. Moreover, the value of $\Delta \Delta G$ (i.e., the difference between attack on the isolated ring and the dibenzothiophene) increased with decreasing activation energy. This is consistent with the increased regioselectivity observed experimentally for activated substrates. Interestingly, the labeling yields also correlate with the Hammett substituent constant $\sigma\left(R^{2}=0.97\right)$ and ${ }^{19} \mathrm{~F}$ chemical shifts $\left(R^{2}=0.83\right)$ of the non-radioactive reference compounds (Figures S14 and S15, SI). While we have not measured the rates of the labeling reactions, the strong correlation of RCYs with the Hammett substitution constant nonetheless provides a valuable tool to predict the outcome of radiochemical reactions. For substrates decorated with complex functional groups, ${ }^{19} \mathrm{~F}$ NMR chemical shifts provide a convenient alternative to determine the suitability of the labeling reaction.

With the aim to demonstrate practicability of the method, we prepared the sulfonium salt precursors of five biologically active compounds, which were subsequently labeled with fluorine-18 (Figure 3). The thioether 10a was used to optimize cyclization conditions (vide supra) and provided the dibenzothiophene sulfonium salt precursor 11a for labeling of $\left[{ }^{18} \mathrm{~F}\right] \mathrm{FPEB}$. This PET tracer, which has been used clinically for imaging of metabotropic glutamate 5 receptors, was particularly pertinent, as our previous attempts at preparing the corresponding triarylsulfonium salt had failed. Using the optimized ring-closing 

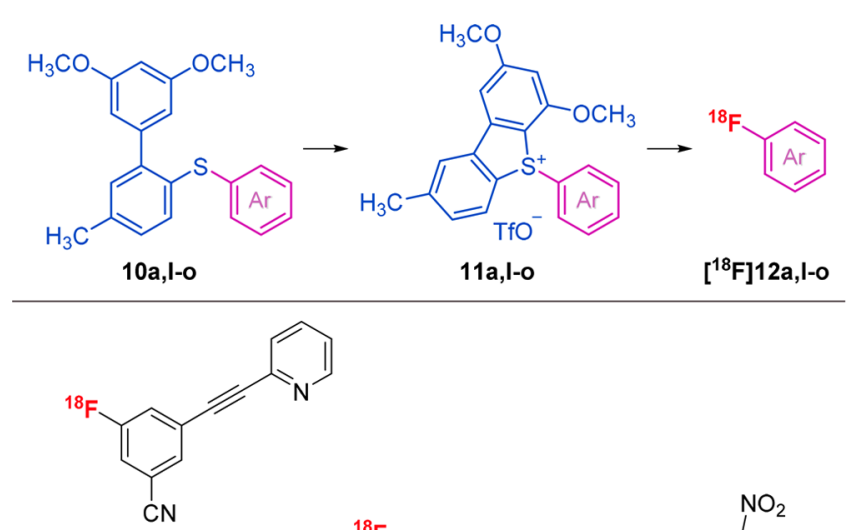

$\left[{ }^{18} \mathrm{~F}\right] \mathrm{FPEB}(\mathbf{1 2 a})$ $55 \pm 3 \%$ RCY

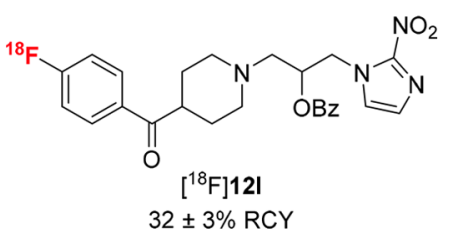

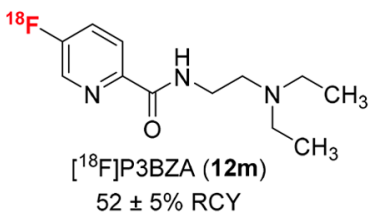
$52 \pm 5 \%$ RCY

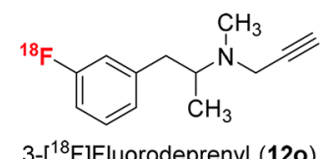
$32 \pm 2 \% \operatorname{RCY}$

Figure 3. Radio-fluorination of biologically relevant tracers with dibenzothiophene sulfonium salts as precursors for labeling.

reaction conditions (Method A), the labeling precursor 11a was obtained in $82 \%$ yield. The resulting white crystalline solid proved stable upon storage at ambient temperature over the course of 3 years (Figure S2, SI). Attempted labeling of 11a under the conditions used for the model compounds $11 \mathbf{b}-\mathbf{k}$ resulted in formation of a radioactive side product, likely due to hydrolysis of the nitrile group (Table S1, SI). The side product was practically eliminated by reducing the temperature and shortening the reaction time. Further optimization revealed that the precursor load could be lowered to $1 \mathrm{mg}$, and the solvent changed to $\mathrm{MeCN}$, without affecting the RCY. In DMSO, the reaction proceeded at $50{ }^{\circ} \mathrm{C}(1 \mathrm{mg}$ precursor, $5 \mathrm{~min})$ to give $\left[{ }^{18} \mathrm{~F}\right]$ FPEB 12a in $75 \%$ RCY as determined by HPLC. An identical RCY was obtained in $\mathrm{MeCN}$ at $80{ }^{\circ} \mathrm{C}$. Under these conditions ( $1 \mathrm{mg}$ precursor, $\mathrm{MeCN}, 80{ }^{\circ} \mathrm{C}, 5 \mathrm{~min}$ ), hands-on labeling afforded $\left[{ }^{18} \mathrm{~F}\right]$ FPEB $12 \mathrm{a}$ in $55 \pm 3 \%$ decay-corrected (d.c.) RCY ( $43 \pm 2 \%$ non-decay-corrected (n.d.c.), Figure 3). The molar activity was $13-20 \mathrm{GBq} \mu \mathrm{mol}^{-1}$, reflecting the low levels of activity used for labeling ( $2 \mathrm{GBq}$ ) due to local constraints.

The high reactivity of 11 a, combined with its ease of synthesis and suitability for long-term storage, demonstrate clear advantages over other labeling strategies reported for this tracer. For example, ${ }^{18} \mathrm{~F}$-fluorination of the corresponding spirocyclic iodonium ylide precursor was recently reported to give $\left[{ }^{18} \mathrm{~F}\right] \mathrm{FPEB}$ in $20 \%$ n.d.c. RCY, whereas copper-mediated labeling of a boronic ester precursor afforded the tracer in a modest $13 \%$ n.d.c. RCY. ${ }^{5,40}$ As the reaction takes place under conditions that mirror nucleophilic substitution reactions with

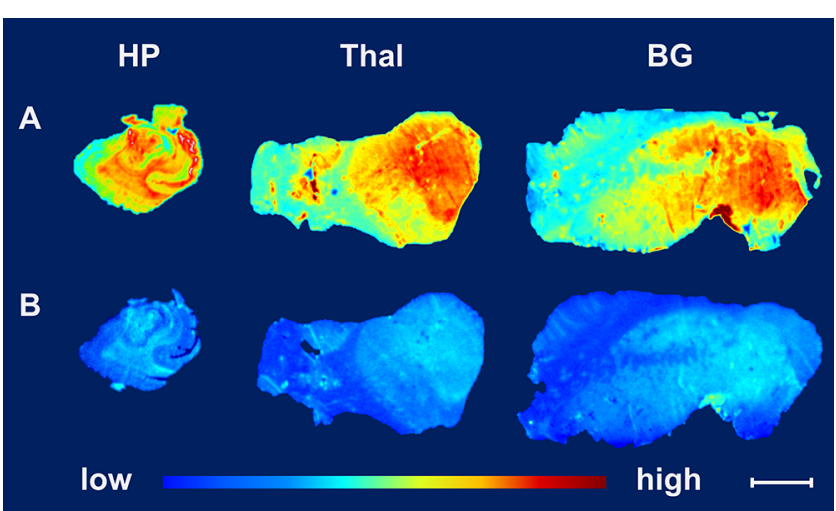

Figure 4. Autoradiography with $3-\left[{ }^{18} \mathrm{~F}\right]$ fluorodeprenyl $\left(\left[{ }^{18} \mathrm{~F}\right] \mathbf{1 2 0}\right)$. Specific binding of the tracer $\left[{ }^{18} \mathrm{~F}\right] \mathbf{1 2 0}$ to human post-mortem brain sections of a case with Alzheimer's disease. Left: medial temporal lobe section with hippocampus and parahippocampal gyrus; center: thalamus with adjacent white matter; right: basal ganglia section with the putamen and caudate nucleus. A: total tracer binding; $\mathrm{B}$ : tracer binding after blocking with the selective MAO-B inhibitor L-deprenyl. Scale bar: $1 \mathrm{~cm}$. Abbreviations: HP, hippocampus; Thal, thalamus; BG, basal ganglia.

$\left[{ }^{18} \mathrm{~F}\right]$ fluoride, the radiosynthesis can readily be automated using conventional equipment and established sequences for trapping and release of $\left[{ }^{18} \mathrm{~F}\right]$ fluoride, labeling, and purification.

With this proof of concept established, we applied the method for labeling of the nitroimidazole $\left[{ }^{18} \mathrm{~F}\right] \mathbf{1 2 1}$, a novel candidate tracer for imaging of hypoxia (Figure 3 ). The sulfonium salt precursor 111 was obtained in 67\% yield (Method A) from the corresponding biaryl thioether 101. Labeling with $\left[{ }^{18} \mathrm{~F}\right]$ fluoride (DMSO, $110{ }^{\circ} \mathrm{C}, 15 \mathrm{~min}$, non-optimized) afforded the target tracer $\left[{ }^{18} \mathrm{~F}\right] \mathbf{1 2 l}$ in $32 \pm 3 \%$ d.c. RCY. The $3-\left[{ }^{18} \mathrm{~F}\right]$ fluoropyridine $12 \mathbf{m}\left(\left[{ }^{18} \mathrm{~F}\right] \mathrm{P} 3 \mathrm{BZA}\right)$ has recently shown promise for imaging of melanoma in patients with metastatic disease; however, the reported radiosynthesis is low yielding. ${ }^{41}$ Initial attempts to synthesize the dibenzothiophene sulfonium salt precursor of $\left[{ }^{18} \mathrm{~F}\right]$ P3BZA $11 \mathrm{~m}$ (Method B) were unsuccessful ( $<10 \%$ yield) when the 2-(diethylamino)ethyl amide side chain was in place. We therefore resolved to cyclize the corresponding ethyl ester (method B, 54\% yield, SI) and subsequently installed the side chain to give $11 \mathrm{~m}$ (92\% yield). Labeling proceeded cleanly to provide $\left[{ }^{18} \mathrm{~F}\right]$ P3BZA $12 \mathrm{~m}$ in $52 \pm 5 \%$ d.c. RCY (DMSO, 110 ${ }^{\circ} \mathrm{C}, 15 \mathrm{~min}$, non-optimized), a substantial improvement on the $12 \pm 4 \%$ RCY reported for the corresponding bromide precursor. ${ }^{41}$ To further evaluate the scope of the pH-buffered cyclization method, we chose the $2-\left[{ }^{18} \mathrm{~F}\right]$ fluoropyridine $12 \mathrm{n}(2$ $\left[{ }^{18} \mathrm{~F}\right]$ fluoro-H-11ONH) as the next target. Gratifyingly, cyclization proceeded smoothly and provided the Boc-protected precursor $11 \mathrm{n}$ in $72 \%$ yield (Method B). ${ }^{18} \mathrm{~F}$-fluorination of $11 \mathrm{n}$ (DMSO, $110{ }^{\circ} \mathrm{C}, 15 \mathrm{~min}$, non-optimized) followed by Boc deprotection afforded $\left[{ }^{18} \mathrm{~F}\right] \mathbf{1 2 n}$ in $41 \pm 3 \%$ d.c. RCY.

Finally, we applied the labeling strategy for development of 3$\left[{ }^{18} \mathrm{~F}\right]$ fluorodeprenyl $\mathbf{1 2 0}$ as a monoamine oxidase B (MAO-B) PET tracer. MAO-B is highly expressed in glial cells and is upregulated in a number of neurodegenerative diseases. ${ }^{16,42}\left[{ }^{11} \mathrm{C}\right]$ $\mathrm{L}$-deprenyl was reported as a MAO-B-selective PET tracer more than 30 years ago, yet attempted development of fluorine-18labeled analogs has so far been unsuccessful, and no other MAO-B-selective ligand has found clinical use for PET imaging. To explore the potential for direct aromatic fluorination of deprenyl, we prepared the corresponding biaryl thioether 10o (3 steps from $\mathbf{5 b}$, $56 \%$ overall yield). Cyclization of 100 proceeded 
smoothly to give the corresponding dibenzothiophene sulfonium salt 110 in $73 \%$ yield (Method A). Subsequent labeling of 11 o with fluorine- 18 (DMSO, $150{ }^{\circ} \mathrm{C}, 15 \mathrm{~min}$, non-optimized) afforded $3-\left[{ }^{18} \mathrm{~F}\right]$ fluorodeprenyl in $32 \pm 2 \%$ d.c. RCY, with a molar activity of $17-30 \mathrm{GBq} \mu \mathrm{mol}^{-1}$ (starting from $2 \mathrm{GBq}$ of $\left[{ }^{18} \mathrm{~F}\right]$ fluoride). Autoradiography with $\left[{ }^{18} \mathrm{~F}\right] \mathbf{1 2 0}$ in human postmortem brain sections of a case with Alzheimer's disease (Figure 4) revealed tracer binding consistent with the expected distribution of MAO-B. The specificity of the signal was confirmed by blocking with the parent compound L-deprenyl. Further development of $\left[{ }^{18} \mathrm{~F}\right] \mathbf{1 2 0}$ as a MAO-B-selective PET tracer is outside the scope of this study and will be reported elsewhere.

\section{CONCLUSIONS}

In summary, we have developed dibenzothiophene sulfonium salts as a novel class of leaving groups for aromatic ${ }^{18} \mathrm{~F}$ fluorination. Intramolecular cyclization of biaryl thioethers gave access to a diverse set of functionalized sulfonium salts under mild conditions. Non-activated and electron-poor substrates reacted regioselectively with $\left[{ }^{18} \mathrm{~F}\right]$ fluoride and gave experimental radiochemical yields that correlated closely with theoretical DFT calculations. The strategy broadens the available radiochemical space and brings the added advantage of superior labeling efficiency for clinically relevant tracers, as exemplified by direct ${ }^{18} \mathrm{~F}$-fluorination of 3-[ $\left[{ }^{18} \mathrm{~F}\right]$ fluorodeprenyl, $\left[{ }^{18} \mathrm{~F}\right] \mathrm{FPEB}$, and $\left[{ }^{18} \mathrm{~F}\right]$ P3BZA.

\section{ASSOCIATED CONTENT}

\section{S Supporting Information}

The Supporting Information is available free of charge on the ACS Publications website at DOI: 10.1021 /jacs.8b06730.

Experimental procedures, spectral and analytical data, and radio-HPLC traces (PDF)

Computational results (ZIP)

\section{AUTHOR INFORMATION}

\section{Corresponding Author}

*e.arstad@ucl.ac.uk

\section{ORCID $\odot$}

Thibault Gendron: 0000-0002-2162-3704

Kerstin Sander: 0000-0002-6096-7577

Michael J. Porter: 0000-0002-0376-5434

Erik Årstad: 0000-0002-3240-2106

\section{Notes}

Ethical approval for the collection of post-mortem human brain tissue was obtained by the Queen Square Brain Bank (QSBB) for Neurological Disorders from the National Research Ethics Service Committee London (Central: 08/H0718/54+5). A patent application has been filed under the international publication number WO2014057291.

The authors declare no competing financial interest.

\section{ACKNOWLEDGMENTS}

The research leading to these results was funded by the European Union's Seventh Framework Programme (FP7/20072013) under grant agreement no. 602102 (EPITARGET, T.G.), the Leonard Wolfson Experimental Neurology Centre, Mallinckrodt (K.S.), UCL Business (HF5E PoC-13-003, T.G.), the Wellcome Trust (102407/Z/13/Z, K.C.), the Clinical Research and Development Committee Research
Funding from the BRC/UCLH Charities (F196, L.B.), CRUK \& EPSRC Comprehensive Cancer Imaging Centre at KCL \& UCL jointly funded by Cancer Research UK, and the Engineering and Physical Sciences Research Council (EPSRC; C1519/A16463), an EPSRC Case Studentship in partnership with GE (P.K.B.S), the UCL MSci in Chemistry (A.K.), and the UCL MRes Organic Chemistry: Drug Discovery Programme (M.W.). The QSBB is supported by the Reta Lila Weston Institute for Neurological Studies and the Progressive Supranuclear Palsy (Europe) Association. This work was undertaken at UCLH/UCL, which is funded in part by the Department of Health's NIHR Biomedical Research Centres funding scheme.

\section{REFERENCES}

(1) Preshlock, S.; Tredwell, M.; Gouverneur, V. Chem. Rev. 2016, 116, 719-766.

(2) Schirrmacher, R.; Wängler, B.; Bailey, J.; Bernard-Gauthier, V.; Schirrmacher, E.; Wängler, C. Semin. Nucl. Med. 2017, 47, 474-492.

(3) Pike, V. W. J. Labelled Compd. Radiopharm. 2018, 61, 196-227.

(4) Tredwell, M.; Preshlock, S. M.; Taylor, N. J.; Gruber, S.; Huiban, M.; Passchier, J.; Mercier, J.; Génicot, C.; Gouverneur, V. Angew. Chem., Int. Ed. 2014, 53, 7751-7755.

(5) Preshlock, S.; Calderwood, S.; Verhoog, S.; Tredwell, M.; Huiban, M.; Hienzsch, A.; Gruber, S.; Wilson, T. C.; Taylor, N. J.; Cailly, T.; Schedler, M.; Collier, T. L.; Passchier, J.; Smits, R.; Mollitor, J.; Hoepping, A.; Mueller, M.; Genicot, C.; Mercier, J.; Gouverneur, V. Chem. Commun. 2016, 52, 8361-8364.

(6) Taylor, N. J.; Emer, E.; Preshlock, S.; Schedler, M.; Tredwell, M.; Verhoog, S.; Mercier, J.; Genicot, C.; Gouverneur, V. J. Am. Chem. Soc. 2017, 139, 8267-8276.

(7) Lee, E.; Kamlet, A. S.; Powers, D. C.; Neumann, C. N.; Boursalian, G. B.; Furuya, T.; Choi, D. C.; Hooker, J. M.; Ritter, T. Science 2011, 334, 639-642.

(8) Lee, E.; Hooker, J. M.; Ritter, T. J. Am. Chem. Soc. 2012, 134, 17456-17458.

(9) Narayanam, M. K.; Ma, G.; Champagne, P. A.; Houk, K. N.; Murphy, J. M. Angew. Chem., Int. Ed. 2017, 56, 13006-13010.

(10) Neumann, C. N.; Hooker, J. M.; Ritter, T. Nature 2016, 534, 369-373.

(11) Rotstein, B. H.; Stephenson, N. A.; Vasdev, N.; Liang, S. H. Nat. Commun. 2014, 5, 4365.

(12) Rotstein, B. H.; Wang, L.; Liu, R. Y.; Patteson, J.; Kwan, E. E.; Vasdev, N.; Liang, S. H. Chem. Sci. 2016, 7, 4407-4417.

(13) Mu, L.; Fischer, C. R.; Holland, J. P.; Becaud, J.; Schubiger, P. A.; Schibli, R.; Ametamey, S. M.; Graham, K.; Stellfeld, T.; Dinkelborg, L. M.; Lehmann, L. Eur. J. Org. Chem. 2012, 2012, 889-892.

(14) Sander, K.; Gendron, T.; Yiannaki, E.; Cybulska, K.; Kalber, T. L.; Lythgoe, M. F.; Årstad, E. Sci. Rep. 2015, 5, 9941.

(15) Sander, K.; Galante, E.; Gendron, T.; Yiannaki, E.; Patel, N.; Kalber, T. L.; Badar, A.; Robson, M.; Johnson, S. P.; Bauer, F.; Mairinger, S.; Stanek, J.; Wanek, T.; Kuntner, C.; Kottke, T.; Weizel, L.; Dickens, D.; Erlandsson, K.; Hutton, B. F.; Lythgoe, M. F.; Stark, H.; Langer, O.; Koepp, M.; Årstad, E. J. Med. Chem. 2015, 58, 6058-6080.

(16) Bernard-Gauthier, V.; Collier, T. L.; Liang, S. H.; Vasdev, N. Drug Discovery Today: Technol. 2017, 25, 19-26.

(17) Haryono, A.; Miyatake, K.; Natori, J.; Tsuchida, E. Macromolecules 1999, 32, 3146-3149.

(18) Iwasaki, T.; Kohinata, Y.; Nishide, H. Org. Lett. 2005, 7, 755758

(19) Vasu, D.; Yorimitsu, H.; Osuka, A. Angew. Chem., Int. Ed. 2015, $54,7162-7166$.

(20) Trost, B. M.; Tamaru, Y. J. Am. Chem. Soc. 1977, 99, 3101-3113.

(21) Chen, C. H.; Reynolds, G. A.; Van Allan, J. A. J. Org. Chem. 1977, 42, 2777-2778

(22) Itoh, T.; Mase, T. J. Org. Chem. 2006, 71, 2203-2206.

(23) Newman, M. S.; Karnes, H. A. J. Org. Chem. 1966, 31, 39803984. 
(24) Lloyd-Jones, G.; Moseley, J.; Renny, J. Synthesis 2008, 2008, 661-689.

(25) Schopfer, U.; Schlapbach, A. Tetrahedron 2001, 57, 3069-3073.

(26) Hamill, T. G.; Krause, S.; Ryan, C.; Bonnefous, C.; Govek, S.; Seiders, T. J.; Cosford, N. D. P.; Roppe, J.; Kamenecka, T.; Patel, S.; Gibson, R. E.; Sanabria, S.; Riffel, K.; Eng, W.; King, C.; Yang, X.; Green, M. D.; O'malley, S. S.; Hargreaves, R.; Burns, H. D. Synapse 2005, 56, 205-216.

(27) Wang, J.-Q.; Tueckmantel, W.; Zhu, A.; Pellegrino, D.; Brownell, A.-L. Synapse 2007, 61, 951-961.

(28) Lambert, R. F.; Hinkle, R. J.; Ammann, S. E.; Lian, Y.; Liu, J.; Lewis, S. E.; Pike, R. D. J. Org. Chem. 2011, 76, 9269-9277.

(29) Olah, G. A.; Wang, Q.; Sandford, G.; Surya Prakash, G. K. J. Org. Chem. 1993, 58, 3194-3195.

(30) Prakash, G. K. S.; Mathew, T.; Hoole, D.; Esteves, P. M.; Wang, Q.; Rasul, G.; Olah, G. A. J. Am. Chem. Soc. 2004, 126, 15770-15776.

(31) Pace, V.; Martínez, F.; Fernández, M.; Sinisterra, J. V.; Alcántara, A. Adv. Synth. Catal. 2009, 351, 3199-3206.

(32) Nabulsi, N. B.; Mercier, J.; Holden, D.; Carre, S.; Najafzadeh, S.; Vandergeten, M.-C.; Lin, S.-f.; Deo, A.; Price, N.; Wood, M.; LaraJaime, T.; Montel, F.; Laruelle, M.; Carson, R. E.; Hannestad, J.; Huang, Y. J. Nucl. Med. 2016, 57, 777-784.

(33) Zhao, Y.; Truhlar, D. G. Theor. Chem. Acc. 2008, 120, 215-241.

(34) The Quantum Theory of Atoms in Molecules: From Solid State to DNA and Drug Design;Matta, C. F., Boyd, R. J., Eds.; WILEY-VCH: Weinheim, 2007; pp 1-34.

(35) Lu, T.; Chen, F. J. Comput. Chem. 2012, 33, 580-592.

(36) Marenich, A. V.; Cramer, C. J.; Truhlar, D. G. J. Phys. Chem. B 2009, 113, 6378-6396.

(37) Mauksch, M.; Schleyer, P. v. R. Inorg. Chem. 2001, 40, 17561769.

(38) Hill, D. E.; Holland, J. P. Comput. Theor. Chem. 2015, 1066, 3446.

(39) Schimler, S. D.; Cismesia, M. A.; Hanley, P. S.; Froese, R. D. J.; Jansma, M. J.; Bland, D. C.; Sanford, M. S. J. Am. Chem. Soc. 2017, 139, $1452-1455$.

(40) Stephenson, N. A.; Holland, J. P.; Kassenbrock, A.; Yokell, D. L.; Livni, E.; Liang, S. H.; Vasdev, N. J. Nucl. Med. 2015, 56, 489-492.

(41) Ma, X.; Shengjun, W.; Wang, S.; Liu, D.; Zhao, X.; Chen, H.; Kang, F.; Yang, W.; Wang, J.; Cheng, Z. J. Nucl. Med. 2018; published ahead of print, DOI: 10.2967/jnumed.118.209643.

(42) Fowler, J. S.; Logan, J.; Shumay, E.; Alia-Klein, N.; Wang, G.-J.; Volkow, N. D. J. Labelled Compd. Radiopharm. 2015, 58, 51-64. 